\title{
IN VITRO CYTOTOXIC AND GAS CHROMATOGRAPHY-MASS SPECTROMETRY STUDIES ON ORTHOSIPHON STAMINEUS BENTH. (LEAF) AGAINST MCF-7 CELL LINES
}

\author{
RENUKA SARAVANAN ${ }^{1}$, BRINDHA PEMIAH ${ }^{2}$, MAHESH NARAYANAN ${ }^{1}$, SIVAKUMAR RAMALINGAM ${ }^{1 *}$ \\ ${ }^{1}$ Department of Chemistry and Biosciences, Srinivasa Ramanujan Centre, SASTRA, University, Kumbakonam, Tamil Nadu, India. ${ }^{2}$ Centre for \\ Advanced Research in Indian System of Medicine, SASTRA University, Thanjavur, Tamil Nadu, India. \\ Email: rsiva@src.sastra.edu \\ Received: 07 October 2016, Revised and Accepted: 16 December 2016
}

ABSTRACT

Objective: The objective of the study was to determine the anticancer efficacy of Orthosiphon stamineus extract against Michigan Cancer Foundation-7 (MCF-7) and its phytochemical analysis through gas chromatography-mass spectrometry (GC-MS).

Methods: Different solvents were used for leaf extraction and used for qualitative assay of phytochemicals using standard protocols. Different concentration $(12.5,25,50,100$, and $200 \mu \mathrm{g} / \mathrm{ml})$ of methanol extract and ethyl acetate extract of 0 . stamineus leaves were used to assess the in vitro cytotoxic effect using 3-(4,5-dimethylthiazol-2-yl)-2,5-diphenyltetrazolium bromide (MTT) assay. Further, the ethyl acetate extract was subjected to GC-MS analysis, and the identification of components was based on the National Institute of Standards and Technology library database.

Result: Of the hexane, methanol and ethyl acetate extracts, methanol extract found to contain more of phytochemicals followed by ethyl acetate. The inhibitory concentration 50 for methanol extract and ethyl acetate extract was found be $93.42 \mu \mathrm{g} / \mathrm{ml}$ and $215.3 \mu \mathrm{g} / \mathrm{ml}$, respectively.

GC-MS mass spectrum of ethyl acetate extract revealed the presence of squalene and phytol and antioxidants such as flavones. Sterols compounds such as vitamin E, ergosterol, cholesterol, and 3,7,11,15-tetramethyl-2-hexadecen-1-ol and terpenoids were also identified.

Conclusion: The data obtained in this work could be useful as a chemical standard in checking the genuineness of this plant source. Data of the results further depicted that the selected traditional anti-cancer plants could be used not only as an anti-cancer but also as a good antioxidant.

Keywords: Anti-cancer, 3-(4,5-dimethylthiazol-2-yl)-2,5-diphenyltetrazolium bromide assay, Orthosiphon stamineus, Michigan cancer fsoundation-7 cells.

(C) 2017 The Authors. Published by Innovare Academic Sciences Pvt Ltd. This is an open access article under the CC BY license (http://creativecommons. org/licenses/by/4. 0/) DOI: http://dx.doi.org/10.22159/ajpcr.2017.v10i3.15575

\section{INTRODUCTION}

Since ancient times, plants are widely used by humankind for treating various ailments due to its rich chemical potentials and eco-friendly nature. Besides these, herbal molecules also provide leads toward drug development for combating deadly diseases such as cancer and could also find immense use in clinical applications [1]. Usage of plants in the management of different diseases and disorders including cancers is the recent approach as observed in the drug development, as it provides a good basis for modern medicines, especially in anti-cancer drug development [2-5].

Literature survey on anticancer studies using plants revealed that they are enriched with an array of chemical compounds which are proven, anticancer agents. Recent researchers are focusing their research toward traditional herbal medicines because the potential of traditional medicines has long been believed and adopted by the people since Vedic period, especially in the management of various ailments [4]. It has been estimated that out of total 2,50,000 plant species existing on earth approximately one thousand species are known to possess anticancer activity. Thousands of plant species have been screened through bioassays for developing novel plant-based molecules that could find use in the management of cancer drugs. Bioactivity-guided isolation is one of the important strategy toward discovering potent anticancer agents from plant sources [6].

Drug discovery from natural products involves screening for specific and non-specific cytotoxicity against many types of cells. Application of in vitro assays for the screening and identification of potential anticancer agents has been a common practice since the beginning of cancer chemotherapy. Chemotherapy is an extremely promising strategy for cancer treatment today, which is defined as the use of synthetic or natural agents (alone or combined) to block the development of cancer in human beings. Today, natural products are focused much for developing cancer chemotherapeutic drugs. Researchers carried on the natural products and drug discovery from seaweeds have resulted in the isolation of over 15,000 novel anti-cancer compounds.

The WHO reported that cancer is a serious health problem and most of the cancer deaths were occurred due to Breast cancer, lung cancer, liver cancer, and stomach cancer [7]. Drug discovery from natural products involves screening for specific and non-specific cytotoxicity against many types of cells. Use of in vitro assays for the screening of potential anticancer agents has been a common practice since the beginning of cancer chemotherapy.

Of various cancer types encountered, breast cancer, is the most frequent malignancy often encountered among women population which is one of the leading cause of death among them, mainly due to the metastatic advancement of the primary stage of this cancer. Hence, need of the hour is to develop a drug for the management of breast cancer from herbal source that could prevent cancer metastasis in these cases and increase the life span of affected women population.

With these views, based on the literature and interviews with traditional herbal healers, a traditional plant source Orthosiphon stamineus is selected for the present work and attempts made to assess its in vitro 
cytotoxic potential against MCF7 cells. MCF7 cells have been extensively used as the model for breast cancer and breast cancer therapy [8].

O. stamineus belonging to the family Lamiaceae is a perennial plant having 4-angled stem with simple leaves. The flowers are white, blue, or violet. Literature references are available on studies carried on extracts and individual compounds isolated from 0 . stamineus which are also evaluated for their antimicrobial, antifungal [9], hypoglycemic, diuretic, litolytic, saluretic [11], anti-inflammatory [12], antioxidant [13], cytotoxic [14], and hypotensive efficacies [15]. Amzad Hossain et al. have isolated a new compound 5, 6, 7, and 8- tetra hydroxy-6-methoxy flavone from this plant which is a proven antibacterial, antifungal, antimicrobial, antitumor, and insect repellant. For the present work hexane, ethyl acetate and methane extracts were prepared by cold maceration method. In the preliminary work of the three extracts, ethyl acetate showed comparatively better anti-proliferating effect against MCF-7 cells.

Even though the rich medicinal properties of 0 . stamineus have been extensively documented, the anti-cancer potential of this plant has been less explored. Hence, in the present study, further in-depth work is carried out to evaluate the anticancer efficacy of the ethyl acetate extract of leaves of $O$. stamineus and to arrive at the probable mechanism of anti-cancer action of the selected extract.

\section{MATERIALS AND METHODS}

Materials

All the chemicals used in this study were procured from Sigma-Aldrich, Himedia, and spectrochem.

\section{Collection of plant materials}

The leaves of 0 . stamineus were collected from Irula Tribal Women's Welfare Society, Thandrai, Tamil Nadu, India. Identification and authentication were confirmed with the help of Flora of Gamble [16]. Vouchers specimen was deposited at the herbarium of the Department of Centre for Advanced Research in Indian System of Medicine, SASTRA University, Thanjavur, Tamil Nadu.

\section{Preparation of plant extract}

Plant material was collected, shade dried, and extracted using standard extraction method [17]. About $25 \mathrm{~g}$ of dried sample was macerated with $150 \mathrm{ml}$ of ethyl acetate separately and kept overnight at room temperature in a shaker. The extract was collected after filtering using Whatman no: 1 filter paper and was stored at $4^{\circ} \mathrm{C}$ till use. Then, the extract was condensed and used for phytochemical screening, gas chromatography-mass spectrometry (GC-MS) analysis, and in vitro cytotoxic assays.

\section{Phytochemical screening [18,19]}

Phytochemical screening of ethyl acetate extract of 0 . stamineus was carried out using standard textual procedures and screened mainly for the presence of carbohydrates, alkaloids, flavonoids, quinones, and triterpenoids.

\section{Test for alkaloids}

About $0.5 \mathrm{~g}$ of crude leaf powder was diluted with $2 \mathrm{~N}$ hydrochloric acid and distilled water. The mixture was heated over a water bath for few minutes, cooled, and filtered. The filtrate was tested by adding alkaloid specific reagents such as Mayer, Wagner's, and Dragendorff.

\section{Test for steroid/triterpenoids}

Crude leaf powder was macerated with $20 \mathrm{ml}$ of hexane for $2 \mathrm{hrs}$ and then filtered. Filtrate was evaporated in the evaporating dish, and then added few drops of Liebermann-Burchard reagent. The onset of blue or blue-green color denotes the presence of steroid, appearance of red, pink or purple indicates the presence of triterpenoids.

\section{Test for flavanoids}

Crude leaf powder was shaken with hot water for 5 minutes and filtered under hot conditions, to the filtrate was added magnesium powder, and concentrated hydrochloric acid and amyl alcohol, then shaken. Development of red or yellow or orange color indicates the presence of flavonoids.

\section{Test for carbohydrates}

Crude leaf powder was mixed with $\alpha$-napthol solution in alcohol and then added few drops of sulfuric acid along the sides of test tubes. The appearance of the violet ring at the junction of two layers confirms the presence of carbohydrates.

\section{Test for quinones}

Crude leaf powder was mixed with $2 \mathrm{ml}$ of $10 \% \mathrm{NaOH}$ solution. The onset of red color indicates the presence of quinones.

The data obtained on various preliminary phytochemical tests were presented in Table 1.

\section{Cell line}

The human breast adenocarcinoma cell lines (MCF7) was obtained from the National Centre for Cell Science, Pune, India. The cells were grown in Eagles Minimum Essential Medium containing 10\% fetal bovine serum (FBS). The cells were maintained at $37^{\circ} \mathrm{C}$, with $5 \% \mathrm{CO}_{2}$ and $100 \%$ relative humidity. Maintenance cultures were passaged weekly, and the culture medium was changed twice a week.

\section{In vitro cytotoxic activity}

The monolayer cells were detached with trypsin- ethylene diamine tetra acetic acid to make single cell suspensions and viable cells were counted using a hemocytometer and diluted with medium containing $5 \%$ FBS to give final density of $1 \times 10^{5}$ cells $/ \mathrm{ml} .100 \mathrm{ml}$ per well of cell suspension were seeded into 96 -well plates at plating density of 10,000 cells/well and incubated using an incubator with $5 \% \mathrm{CO}_{2}, 95 \%$ air, and $100 \%$ relative humidity at $37^{\circ} \mathrm{C}$ to allow for cell attachment. After $24 \mathrm{hrs}$, the cells were treated with serial concentrations of the test samples. They were initially dissolved in neat dimethyl sulfoxide (DMSO) and an aliquot of the sample solution was diluted to twice the desired final maximum test concentration with serum-free medium. Additional four serial dilutions were made to provide a total of five sample concentrations. Aliquots of $100 \mu \mathrm{l}$ of these different sample dilutions were added to the appropriate wells already containing $100 \mu \mathrm{l}$ of medium, resulting in the required final sample concentrations. Following sample addition, the plates were incubated for an additional $48 \mathrm{hrs}$ at $37^{\circ} \mathrm{C}$, under the same incubating conditions as mentioned above. The medium without samples served as control and triplicates were maintained for all concentrations. $5 \mathrm{mg}$ of ethyl acetate extract was dissolved in $100 \mu \mathrm{l}$ of DMSO and then diluted with culture media to get a series of concentrations such as $12.5,25,50,100$, and $200 \mu \mathrm{g} / \mathrm{ml}$. The culture media was used as negative control, and Taxol was used as positive control with series of concentration ranging from $0.001,0.01,0.1$, and 1 to $10 \mu \mathrm{g}$.

\section{Cytotoxic assay using MTT method}

Succinate-dehydrogenase, is a mitochondrial enzyme in living cells, that reacts with 3-[4,5-dimethylthiazol-2-yl] 2,5-diphenyltetrazolium bromide (MTT) a yellow water-soluble tetrazolium salt and forms an insoluble purple formazan. In this process, the tetrazolium ring is cleaved, and MTT is converted to this insoulbe purple formazan. The amount of formazan thus produced is directly proportional to the number of viable cells. Hence, amount of formazan produced is useful in counting viable and non-viable cells and in assessing the cytotoxic potential.

After $48 \mathrm{hrs}$ of incubation, $15 \mu \mathrm{l}$ of MTT $(5 \mathrm{mg} / \mathrm{ml})$ in phosphatebuffered saline was added to each well and incubated at $37^{\circ} \mathrm{C}$ for $4 \mathrm{hrs}$. The medium with MTT was then flicked off, and the formed formazan crystals were solubilized in $100 \mu \mathrm{l}$ of DMSO and the absorbance measured at $570 \mathrm{~nm}$ using microplate reader. The percentage cell inhibition was determined using the following formula: 
$\%$ cell inhibition $=100-$ Abs $($ sample $) /$ Abs $($ control $) \times 100$.

Nonlinear regression graph was plotted between \% cell inhibition and Log concentration, and inhibitory concentration $\left(\mathrm{IC}_{50}\right)$ was determined using GraphPad Prism software.

\section{GC-MS analysis}

\section{Instruments and chromatographic conditions}

GC-MS analysis of ethyl acetate extract of 0 . stamineus was performed using the equipment PerkinElmer Clarus 500 GC-MS. The equipment has Elite-5 non-polar capillary column with dimensions of $30 \mathrm{~m} \times 0.25 \mathrm{~mm}$ ID $\times 0.25 \mu \mathrm{m}$ film thickness. The carrier gas used is helium (99.999\% purity) with a flow rate of $1 \mathrm{ml} /$ minute. The injector temperature was maintained at $280^{\circ} \mathrm{C}$, and the oven temperature was programmed as follows: Initial temperature was $60^{\circ} \mathrm{C}$, gradually increased to $150^{\circ} \mathrm{C}$ with an increase of $6^{\circ} \mathrm{C} /$ minute hold for 2 minutes, and then increased by $4^{\circ} \mathrm{C} /$ minute to $280^{\circ} \mathrm{C}$ hold for 10 minutes. Mass spectra were taken at $70 \mathrm{ev}$, and the resulted fragments were scanned from 40 to $450 \mathrm{Da}$ with a scan interval of 0.5 second. The identification of components was based on the National Institute of Standards and Technology library database and the results obtained were tabulated and presented.

\section{RESULTS AND DISCUSSION}

In the present work, a traditional anti-cancer plant source 0 . stamineus belonging to the family lamiaceae is selected and evaluated for its in vitro cytotoxic potential as well anti-cancer molecules present in the text; extract was also identified.

Preliminary phytochemical screening of selected extracts of 0 . stamineus revealed the presence of interesting phytochemicals (Table 1).

Hexane extract showed the presence of terpenoids and sterols. Ethyl acetate extract of leaves revealed the presence of carbohydrates, flavonoids, alkaloids, quinones, terpenoids, triterpenoids, phenol, and coumarins. Methanolic extract contains flavonoids and alkaloids.

\section{Therapeutic efficacy of the major constituents detected in the} chemical analysis

In the preliminary chemical analysis and GC-MS studies flavonoids, alkaloids, quinones, terpenoids, phenol, and coumarins were found to be present. Existing reports on the anti-cancer efficacies of these phytoconstituents were reviewed and discussed in sequel.

The anti-cancer activity of terpenoids has been well documented [20]. Alkaloids found in plants are used as potent anticancer agent against various types of cancer. Vinblastine and vincristine are the first anticancer alkaloids identified in plants and are currently used in the

Table 1: Preliminary phytochemical screening of the various extracts of the 0 . stamineus

\begin{tabular}{llll}
\hline Test for & Hexane & Ethyl acetate & Methanol \\
\hline Carbohydrate & - & + & + \\
Tannins & - & - & - \\
Saponins & - & - & - \\
Flavonoids & - & + & + \\
Alkaloids & + & + & + \\
Quinones & - & + & + \\
Glycosides & - & - & - \\
Terpenoids & + & - & + \\
Triterpenoids & - & + & + \\
Phenols & - & - & + \\
Coumarins & - & + & + \\
Proteins and amino acids & - & - & - \\
Steroids and phytosterols & + & - & - \\
Phlobatanins & - & - & - \\
Anthraquinones & - & - & - \\
\hline O. Stamineus: Orthosiphon stamine & & \\
\hline
\end{tabular}

O. stamineus: Orthosiphon stamineus treatment variety of cancers such as leukemia, lymphomas, advanced testicular cancer, breast, and lung cancer and in Kaposi's sarcoma [21].

Flavonoids identified are another group of chemicals which are proven anti-cancer agents [22]. Natural or synthetic quinones also reveal antitumoral activity. Coumarins which are found to be present belong to class of compounds which display interesting biological activities including anticancer activity [23]

Ethyl acetate extract of leaf of 0 . stamineus the selected plant of the present work revealed the presence of all these proven anti-cancer flavonoids, alkaloids, quinones, terpenoids, triterpenoids, phenol, and coumarins. Comparatively better anti-cancer activity exhibited by the selected extract of the plant studied may be due to the presence of these phytochemicals. Hence, ethyl acetate extract is further subjected to anti-cancer studies employing in vitro methods and GC-MS analysis also carried out to detect various fragment's pattern present in the test extract. The data of these studies helped in providing scientific evidence for the proposed anti-cancer action of the ethyl acetate extract of $O$. stamineus leaf.

\section{In vitro studies}

Fig. 1 represents the cytotoxic efficacy and the data of the MTT assay, carried out in hexane, ethyl acetate, and methanol extracts of o. stamineus leaves against MCF7 cells.

The $\mathrm{IC}_{50}$ of methanol and ethyl acetate extract of 0 . stamineus leaves was found to be $93.42 \mu \mathrm{g} / \mathrm{ml}$ and $215.3 \mu \mathrm{g} / \mathrm{ml}$, respectively (Fig. 2a and b).

Of these extracts, ethyl acetate extract exhibited highest cytotoxic activity against breast cancer cells due to its rich chemical potentials.

Fig. 3 to 12 provides GC-MS chromatogram and specific mass spectrum of anti-cancer compounds identified in the test extracts such as squalene and phytol and antioxidant compounds such as flavones and vitamin E. some sterols and terpenoids were also detected such as ergosterol, cholesterol, and 3,7,11,15-tetramethyl-2-hexadecen-1-ol that might possess anti-cancer activity.

Fig. 4 gives the mass spectrum of flavone, 3-hydroxy-3',4',5,7tetramethoxy a fragmentation pattern of a flavone type, which are proven anti oxidants.

Fig. 5 presence the mass spectrum of Chola-5,22-dien-3-ol, (3á,22E) a fragment of a sterol.

Fig. 6 gives the mass spectrum of Vitamin $\mathrm{E}$ a known anti oxidant.

Fig. 7 shows the mass spectrum of Ergost-8(14)-en-3-ol, (3á).

Fig. 8 shows the mass spectrum of Squalene an anti cancer triterpenoid compound.

Fig. 9 shows the mass spectrum of 1,2,3,4-tetrahydro-3(phenylacetamido) quinoline an alkaloidal fragment.

Fig. 10 shows the mass spectrum of Phytol an anti cancer diterpene alcohol.

Fig. 11 shows the mass spectrum of 3,7,11,15-Tetramethyl-2-hexadecen1-ol which is a terpenol fragment.

Fig. 12 shows the mass spectrum of pyrrolo[1,2-c]oxazol-1(3H)-one, tetrahydro 7a-acetyl-3-(1,1-dimethylethyl) an azole derivative.

One of the possible mechanism of anti-cancer actions of the test drug may be through the maintenance of the antioxidant status which might be due to the presence of antioxidant molecules. GC-MS analysis revealed the presence of squalene an anti-cancer terpenoid, an alkaloidal fragment, and phytol an anti-cancer diterpene alcohol. 

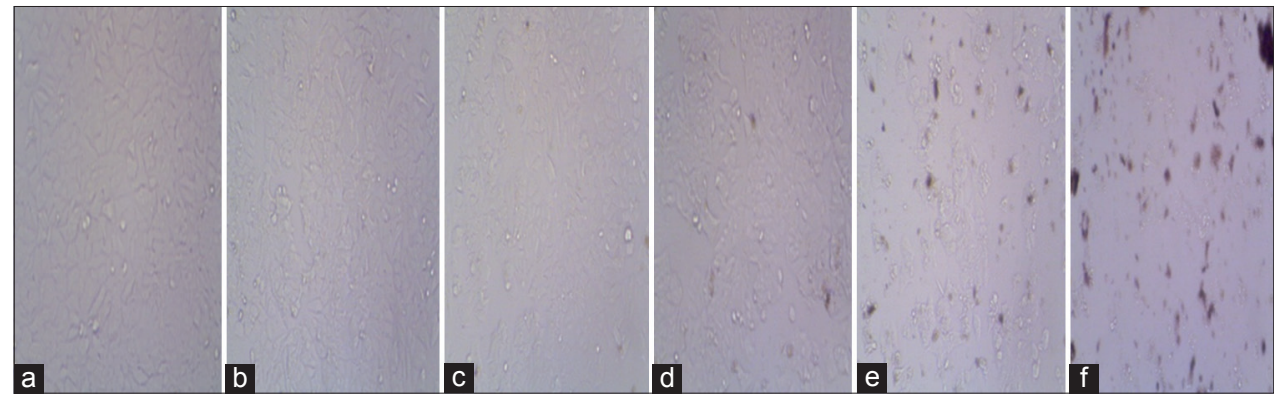

Fig. 1: Cytotoxic efficacy of Orthosiphon stamineus leaf extract on Michigan Cancer Foundation-7 cell line (a) Normal Michigan Cancer Foundation-7 cell line 2, (b) toxicity at $12.5 \mu \mathrm{g} / \mathrm{ml}$, (c) toxicity at $25 \mu \mathrm{g} / \mathrm{ml}$, (d) toxicity at $50 \mu \mathrm{g} / \mathrm{ml}$, (e) toxicity at $100 \mu \mathrm{g} / \mathrm{ml}$,

(f) toxicity at $200 \mu \mathrm{g} / \mathrm{ml}$
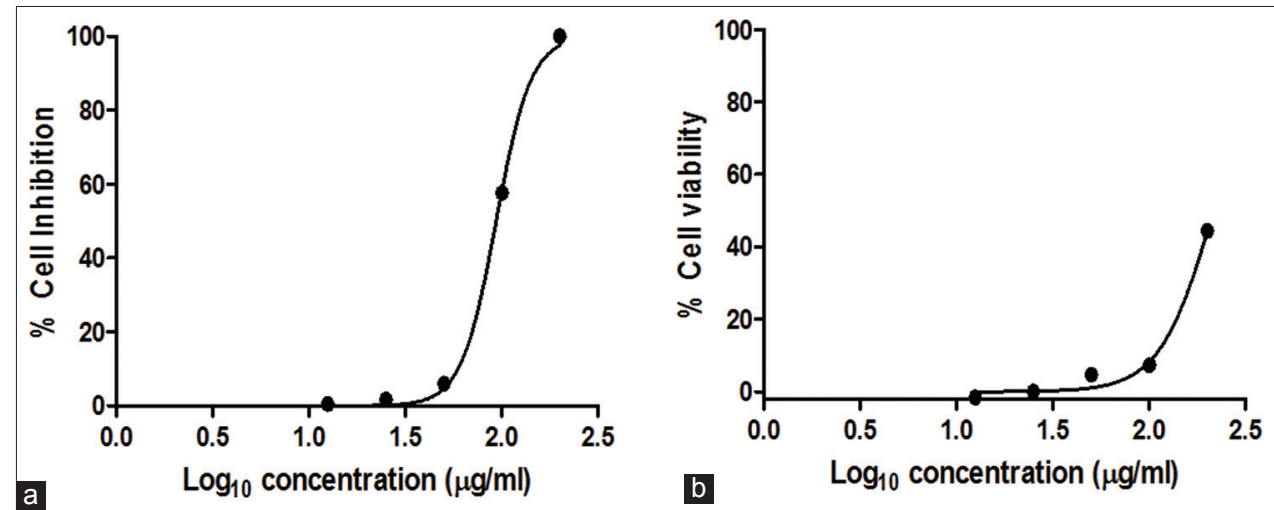

Fig. 2: (a and b) Effect of various concentrations of methanol and ethyl acetate extracts of Orthosiphon stamineus- leaves on Michigan Cancer Foundation-7 cell lines (3-(4,5-dimethylthiazol-2-yl)-2,5-diphenyltetrazolium bromide assay)

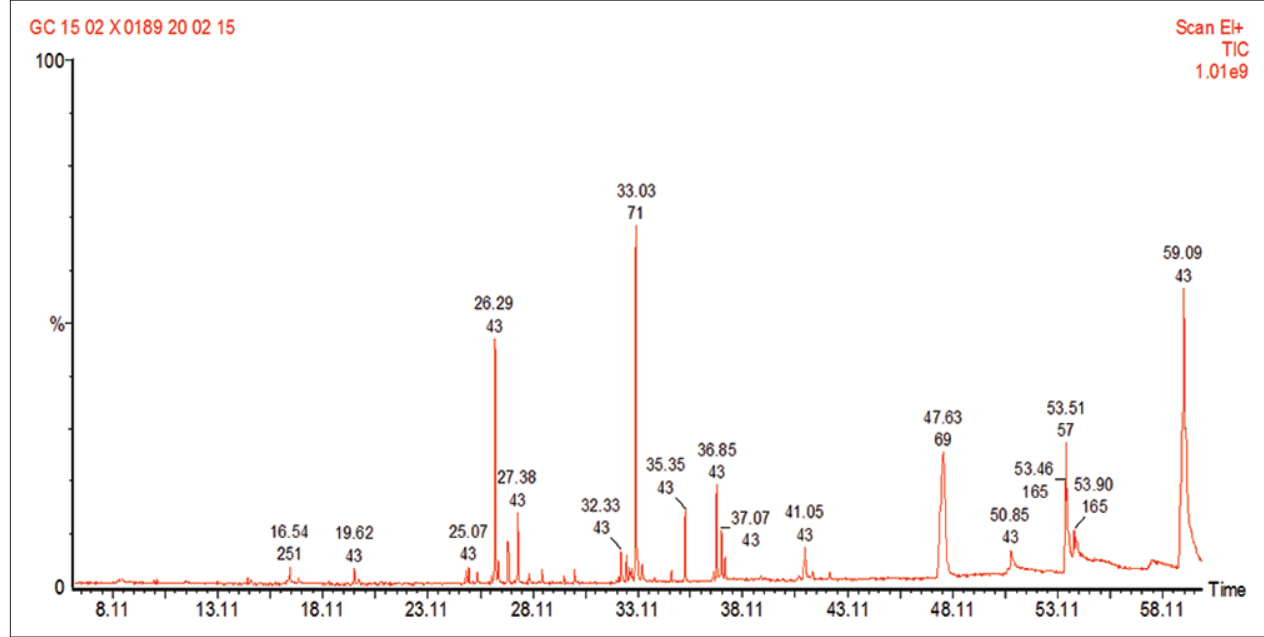

Fig. 3: Gas chromatography-mass spectrometry chromatogram of ethyl acetate extract of Orthosiphon stamineus

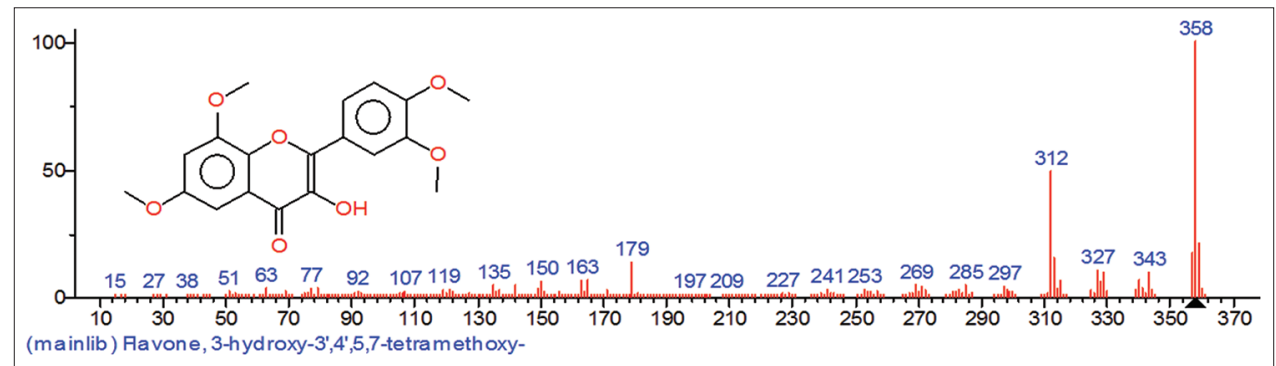

Fig. 4: Mass spectrum of flavone, 3-hydroxy-3',4',5,7-tetramethoxy- (RT:59.09) 


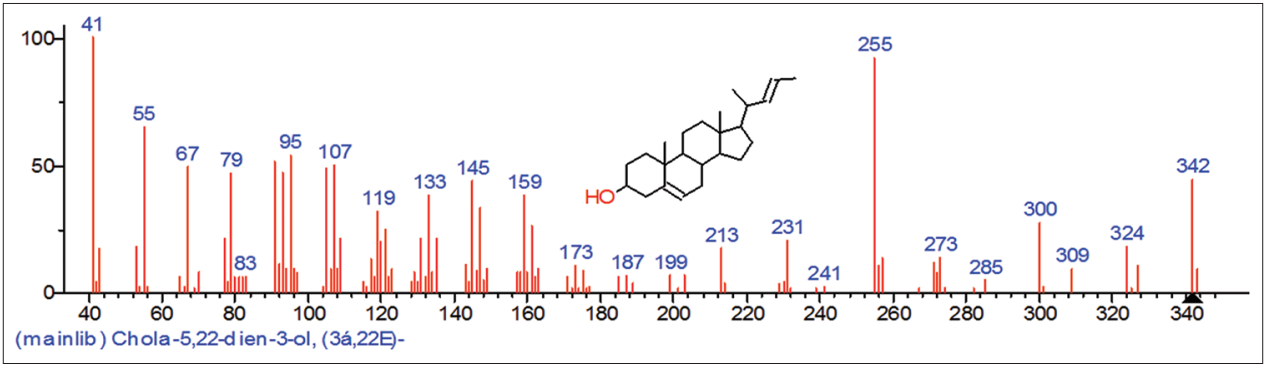

Fig. 5: Mass spectrum of chola-5,22-dien-3-ol, (3á,22E)- (RT: 57.61)

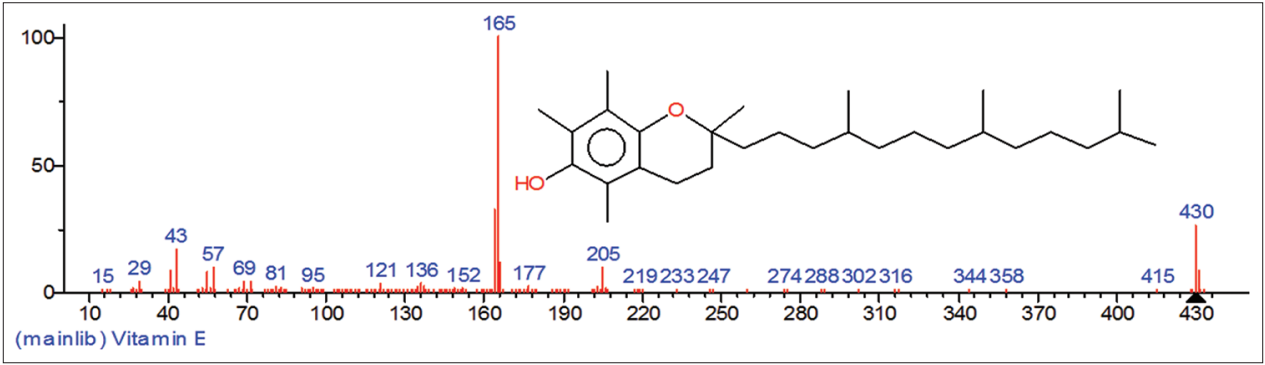

Fig. 6: Mass spectrum of Vitamin E (RT:53.46)

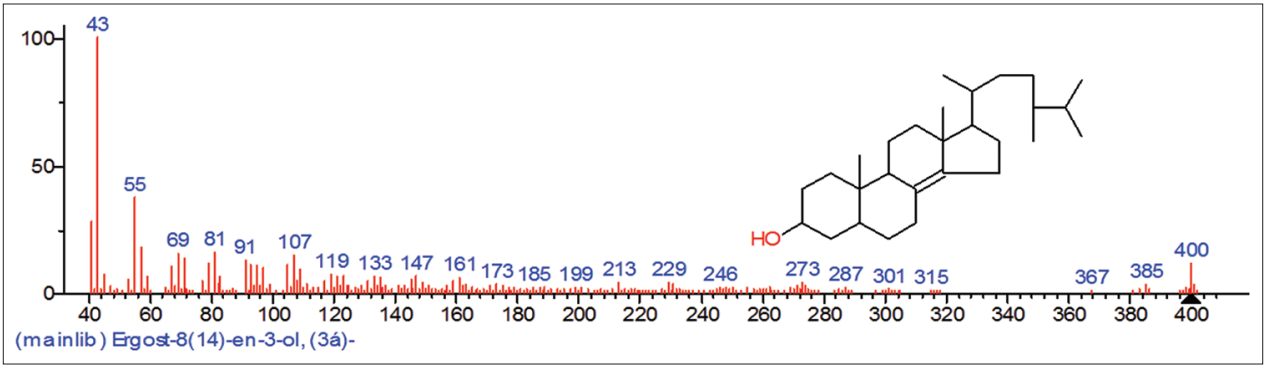

Fig. 7: Mass spectrum of Ergost-8(14)-en-3-ol, (3á)- (RT: 50.75)

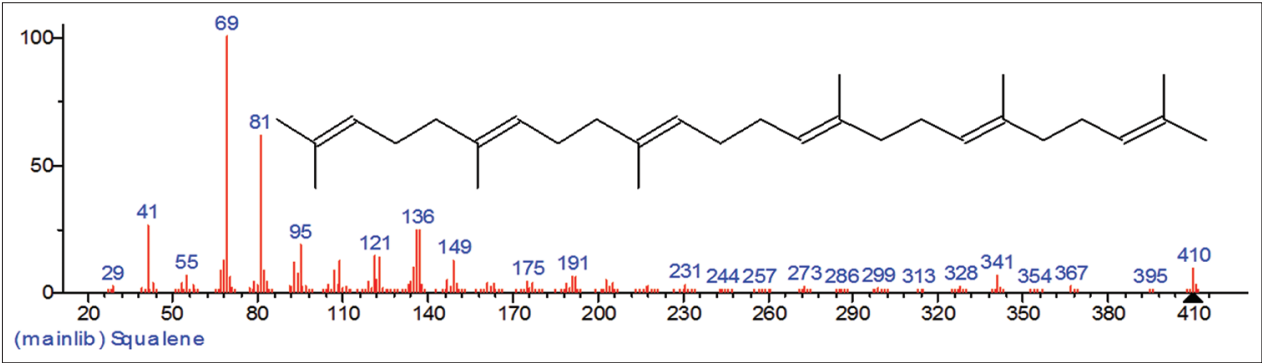

Fig. 8: Mass spectrum of squalene (RT:47.63)

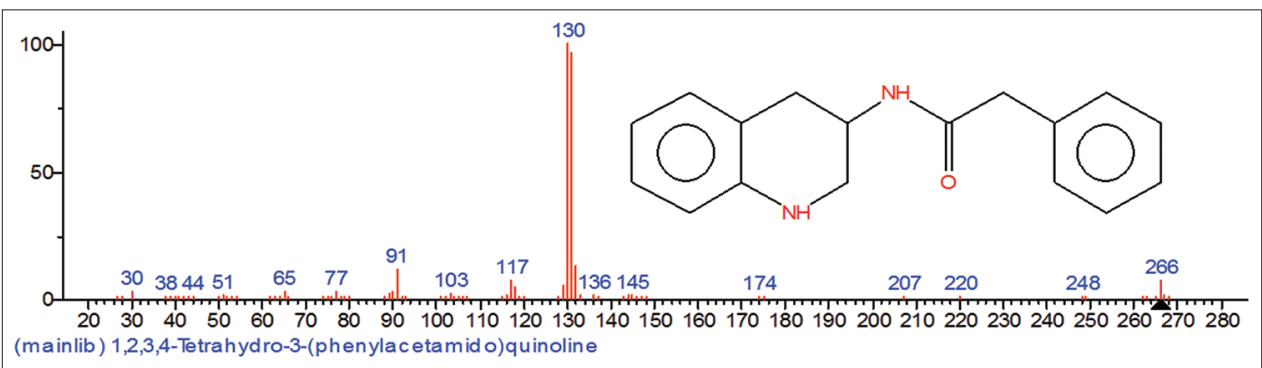

Fig. 9: Mass spectrum of 1,2,3,4-Tetrahydro-3-(phenylacetamido) quinoline (RT:40.75) 


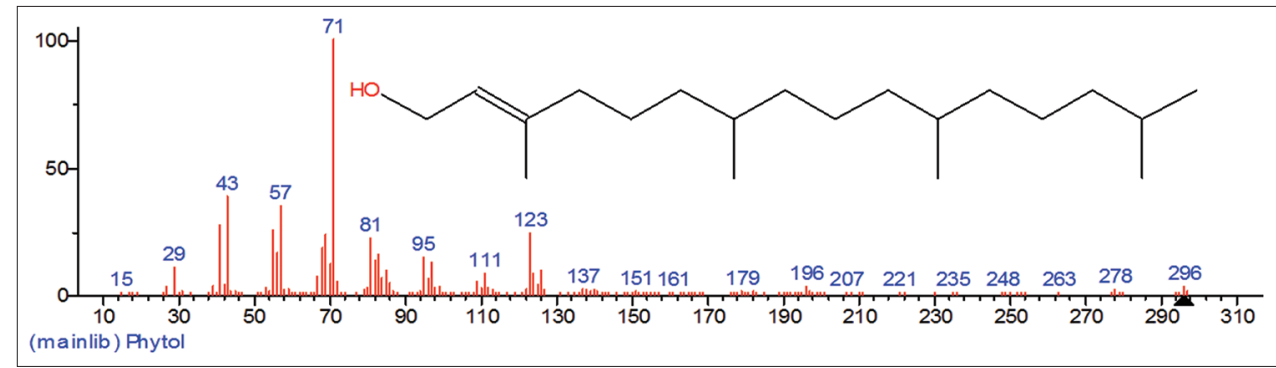

Fig. 10: Mass spectrum of phytol (RT:33.03)

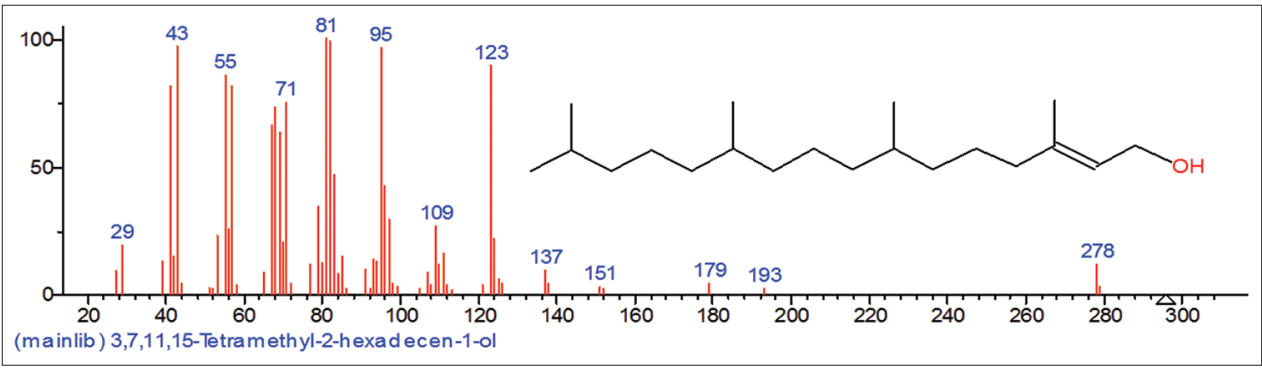

Fig. 11: Mass spectrum of 3,7,11,15-tetramethyl-2-hexadecen-1-ol (RT:26.29)

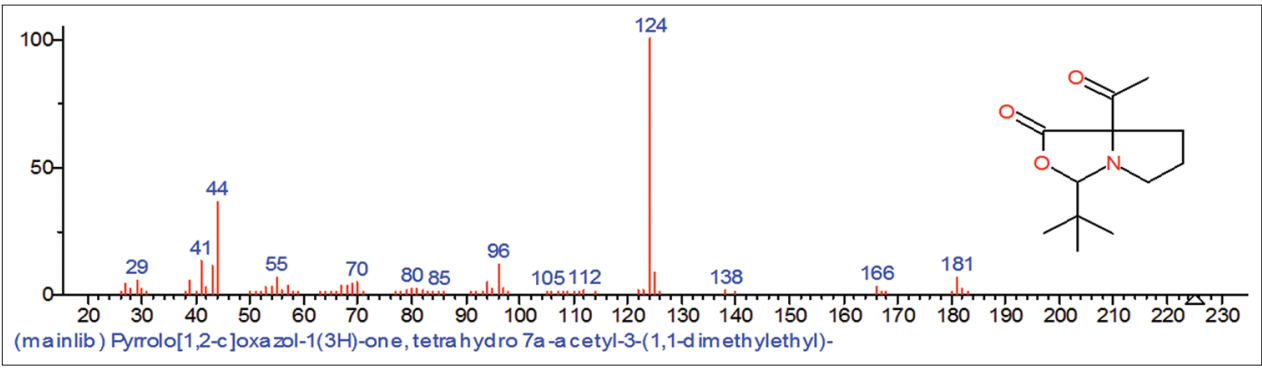

Fig. 12: Mass spectrum of pyrrolo [1,2-c]oxazol-1(3H)-one, tetrahydro 7a-acetyl-3-(1,1-dimethylethyl)-(RT:25.46)

Further, this also suggested the presence of antioxidant flavones and vitamin $\mathrm{E}$, thus provided supporting chemical evidence for the cytotoxic efficacy and antioxidant potential of selected extract.

These constituents might have helped in preventing cancer progress by arresting cell proliferation. The data obtained on the MTT assay depicted that ethyl acetate extract of the selected plant might have activated apoptosis due to the presence of quinones and alkaloids which play major role in inducing apoptosis. Besides, similar previous studies have shown that these phytoconstituents also can be useful in preventing further development of cancer by controlling the proliferation of cancer [23].

\section{CONCLUSION}

In the present studies, 0 . stamineus leaf extract was selected and screened for its cytotoxic effect against MCF7 cell lines with a view to suggest an anti- cancer herbal drug for managing breast cancer. Preliminary phytochemical screening of various extracts revealed the presence of quinones, flavones, and alkaloids which are proven anticancer phytoconstituents.

To conclude, GC-MS data obtained in this work could be useful as a chemical standard in checking the genuineness of this plant source. Data of the results further depicted that the selected traditional anticancer plants could be used not only as an anti-cancer but also as a good anti-oxidant.

From the data obtained in the present work, it may be concluded that the selected plant $O$. stamineus could be useful not only as an anti-cancer agent but also could be useful as a good anti-oxidant.

\section{REFERENCES}

1. Balunas MJ, Kinghorn AD. Drug discovery from medicinal plants. Life Sci 2005;78(5):431-41

2. Jones WP, Chin YW, Kinghorn AD. The role of pharmacognosy in modern medicine and pharmacy. Curr Drug Targets 2006;7(3):247-64.

3. Kim J. Protective effects of Asian dietary items on cancers - Soy and ginseng. Asian Pac J Cancer Prev 2008;9(4):543-8.

4. Aune D, De Stefani E, Ronco A, Boffetta P, Deneo-Pellegrini H, Acosta $\mathrm{G}$, et al. Fruits, vegetables and the risk of cancer: A multisite case-control study in Uruguay. Asian Pac J Cancer Prev 2009;10(3):419-28.

5. Hasan TN, Grace BL, Shafi G, Al-Hazzani AA, Alshatwi AA. Antiproliferative effects of organic extracts from root bark of Juglans regia L. (RBJR) on MDA-MB-231 human breast cancer cells: Role of Bcl-2/Bax, caspases and Tp53. Asian Pac J Cancer Prev 2011;12(2):525-30.

6. Rajendran S, Saravanan R, Ramalingam S, Hameed SA. Antiproliferative and antioxidant activity of Gynandropsis pentaphylla LINN on MCF-7 Cell line. Int J Pharm Pharm Sci 2014;6:561-5.

7. Stewart BW, Wild CP, editors. World Cancer Report 2014. Lyon, France: International Agency for Research on cancer.

8. Subramaniyan V, Saravanan R, Baskaran D, Ramalalingam S. In vitro free radical scavenging and anticancer potential of Aristolochia indica L. Against Mcf-7cell line. Int J Pharm Pharm Sci 2015;7(6):392-6.

9. Hossain MA, Ismail Z, Rahman A, Kang SC. Chemical composition and anti-fungal propertiesof the essential oils and crude extracts of Orthosiphon stamineus Benth. Ind Crop Prod 2008;27:328-34.

10. Dharmaraj S, Hossain MA, Zhari S, Harn GL, Ismail Z. The use of principal componentanalysis and selforganizing map to monitor inhibition of calcium oxalate crystal growth by Orthosiphon stamineus 
extract. Chemometr Intell Lab Syst 2006;81(2):21-8

11. Awale S, Tezuka Y, Banskota AH, Adnyana IK, Kadota S. Highlyoxygenated isopimarane-type diterpenes from Orthosiphon stamineus of Indonesia and their nitric oxide inhibitory activity. Chem Pharm Bull (Tokyo) 2003;51(3):268-75.

12. Akowuah GA, Ismail Z, Norhayati I, Sadikun A. The effects of different extraction solvents of varying polarities on polyphenols of Orthosiphon stamineus and evaluation of the free radical-scavenging activity. Food Chem 2005;93:311-7.

13. Tezuka Y, Stampoulis P, Banskota AH, Awale S, Tran KQ, Saiki I, et al. Constituents of the Vietnamese medicinal plant Orthosiphon stamineus. Chem Pharm Bull (Tokyo) 2000;48(11):1711-9.

14. Matsubara T, Bohgaki T, Watarai M, Suzuki H, Ohashi K, Shibuya H. Antihypertensive actions of methylripariochromene A from Orthosiphon aristatus, an Indonesian traditional medicinal plant. Biol Pharm Bull 1999;22(10):1083-8.

15. Gamble JS. Flora of the Presidency of Madras. Vol. 2. Dehradun: Bishen Singh Mahendra Pal Singh Dehra Dun; 2008. p. 1115.

16. Manjamalai A, Narala Y, Haridas A, Grace VM. Antifungal, antiinflammatory and GC-MS analysis of methanolic extract of
Plectranthus amboinicus leaf. Int J Curr Pharm Res 2011;2:129-36.

17. Harbone JB. Phytochemical Methods. $2^{\text {nd }}$ ed. Bandung: Padmawinata; 1987.

18. Harbone JB. Phytochemical Methods. $3^{\text {rd }}$ ed. London: Chapman and Hill; 1998

19. Ayoola GA. Phytochemical screening and antioxidant activities of some selected medicinal plants used for malaria therapy in Southwestern Nigeria. Trop J Pharm Res 2008;7(3):1019-24.

20. Cragg GM, Newman DJ. Plants as a source of anti-cancer agents. J Ethnopharmacol 2005;100(1-2):72-9.

21. Schuier M, Sies H, Illek B, Fischer H. Cocoa-related flavonoids inhibit CFTR-mediated chloride transport across T84 human colon epithelia. J Nutr 2005;135(10):2320-5.

22. Cheng JH, Hung CF, Yang SC, Wang JP, Won SJ, Lin CN. Synthesis and cytotoxic, anti-inflammatory, and anti-oxidant activities of 2', 5 '-dialkoxylchalcones as cancer chemopreventive agents. Bioorg Med Chem 2008;16(15):7270-6

23. Ravichandran N, Rajalakshmi P, Raj CD, Arun KP, Brindha P. Standardization and in vitro cytotoxic studies on Narasimha lehiyam: A potent anticancer Siddha drug. Asian J Chem 2014;26(12);3692-6. 